\title{
Painless Colonoscopy: Available Techniques and Instruments
}

\author{
Hyun Gun Kim \\ Institute for Digestive Research, Soon Chun Hyang University College of Medicine, Seoul, Korea
}

During colonoscopy, air insufflation to distend the lumen and facilitate careful inspection and scope insertion can induce pain and cause discomfort. Carbon dioxide $\left(\mathrm{CO}_{2}\right)$ insufflation can decrease abdominal pain and discomfort during and after colonoscopy. The advantage of $\mathrm{CO}_{2}$ insufflation is the rapid absorption of the gas across the intestine. Another painless option is water-assisted colonoscopy. Two methods for water-assisted colonoscopy are available: water immersion and water exchange. In a recent direct comparison, the water exchange method was superior to water immersion, $\mathrm{CO}_{2}$ insufflation, and air insufflation with respect to pain during colonoscopy, although it still had the disadvantage of being a time-consuming procedure. Cap-assisted colonoscopy is a simple technique involving the use of a small transparent cap attached to the tip of the scope. Three studies showed an advantage of this technique in terms of reduced patient discomfort compared with the conventional method. Three robotic colonoscopy systems (Endotics System [Era Endoscopy], NeoGuide [NeoGuide Systems Inc.], and Invendoscope [Invendo Medical]) have been introduced to evaluate pain reduction during colonoscopy, but none has been widely adopted and used in practice. In this review, clinical trials of several techniques and new devices for painless colonoscopy are described and summarized. Clin Endosc 2016;49:444-448

Key Words: Colonoscopy; $\mathrm{CO}_{2}$ insufflation; Water-assisted colonoscopy

\section{INTRODUCTION}

Careful inspection is important in detecting precancerous lesions during colonoscopy. Adequate bowel preparation and appropriate luminal distention are essential for inspection, allowing visualization of the entire colonic mucosa, and performance of adequate colonoscopy, defined as an adenoma detection rate $\geq 25 \%$. ${ }^{1}$ Total insufflated air volume during colonoscopy is typically 8 to $18 \mathrm{~L}^{2}$ However, air insufflation (AI) can cause pain and discomfort, especially when the scope is passed through the sigmoid or transverse colon. Several methods to avoid painful colonoscopy have been introduced, and new robotic methods, although not widely used, have also

Received: September 6, 2016 Revised: September 19, 2016

Accepted: September 19, 2016

Correspondence: Hyun Gun Kim

Institute for Digestvie Research, Soon Chun Hyang University Seoul Hospital, Soon Chun Hyang University College of Medicine, 59 Daesagwan-ro, Yongsan-gu, Seoul 04401, Korea

Tel: +82-2-710-3072, Fax: +82-2-7009-9868, E-mail: medgun@schmc.ac.kr

(cc) This is an Open Access article distributed under the terms of the Creative Commons Attribution Non-Commercial License (http://creativecommons.org/ licenses/by-nc/3.0) which permits unrestricted non-commercial use, distribution, and reproduction in any medium, provided the original work is properly cited. been introduced. This review describes various techniques for painless colonoscopy, including gaseous methods, water-immersion methods, and others.

\section{CARBON DIOXIDE INSUFFLATION}

Carbon dioxide $\left(\mathrm{CO}_{2}\right)$ gas causes less pain than room air during colonoscopy. $\mathrm{CO}_{2}$ is absorbed across the intestine 160 times more rapidly than nitrogen and 13 times faster than oxygen. ${ }^{3}$ The first use of $\mathrm{CO}_{2}$ insufflation in endoscopic procedures was in colonoscopy. In a 1984 report, Hussein et al. ${ }^{4}$ compared postcolonoscopy discomfort in $\mathrm{a}_{2}$ insufflation group and an $\mathrm{AI}$ group. The $\mathrm{CO}_{2}$ insufflation group showed no significant residual abdominal gas on plain radiographs 30 minutes after colonoscopy and much less discomfort than the AI group, which showed large amounts of gas on radiographs. Since these data were reported, more than 20 randomized controlled trials (RCTs) on the effectiveness of $\mathrm{CO}_{2}$ versus AI have been published. Moreover, three metaanalyses and one systematic review based on previous RCTs have recently provided useful information on clinical outcomes of $\mathrm{CO}_{2}$ gas 
in colonoscopy practice. ${ }^{5-8}$ According to the latest meta-analysis, based on 24 RCTs, and previous meta-analyses and a systematic review, $\mathrm{CO}_{2}$ gas insufflation is significantly superior to $\mathrm{AI}$ in terms of intraprocedural pain and discomfort. ${ }^{8}$ Early postprocedural pain at 2 hours after colonoscopy, intermediate pain at 6 hours after colonoscopy, and late pain at 24 hours after colonoscopy were compared, and $\mathrm{CO}_{2}$ insufflation was superior to $\mathrm{AI}$ at all times for reducing postprocedural pain and flatus. ${ }^{6}$

In colonoscopy performance, $\mathrm{CO}_{2}$ insufflation did not show an improvement in cecal intubation time or rate compared with $\mathrm{AI}^{8}{ }^{8}$ Regarding safety, end-tidal $\mathrm{CO}_{2}\left(\mathrm{ETCO}_{2}\right)$ levels during and after the procedure were not significantly different between the $\mathrm{CO}_{2}$ and $\mathrm{AI}$ groups. ${ }^{6}$ Sedation during colonoscopy also did not affect the $\mathrm{ETCO}_{2}$ level in the $\mathrm{CO}_{2}$ and $\mathrm{AI}$ groups. ${ }^{9}$ Other than the $\mathrm{ETCO}_{2}$ level, adverse events related to $\mathrm{CO}_{2}$ insufflation during colonoscopy have not been reported, or showed no difference compared with conventional AI colonoscopy. ${ }^{8}$

Evidence for the safety of $\mathrm{CO}_{2}$ insufflation colonoscopy in high-risk conditions, including chronic obstructive pulmonary disease, severe cardiac disease, sleep apnea, and morbid obesity, is still very limited, and caution should be exercised in using $\mathrm{CO}_{2}$ insufflation during in these groups. Regarding exposure to $\mathrm{CO}_{2}$ during colonoscopy, recent evidence showed that there was no difference in intraprocedural or postprocedural pain levels between a scope extubation-only $\mathrm{CO}_{2}$ insufflation group and a whole-procedure $\mathrm{CO}_{2}$ insufflation group; thus, both partial-procedure $\mathrm{CO}_{2}$ insufflation and extubation-only $\mathrm{CO}_{2}$ insufflation can be used to decrease postprocedural discomfort and pain. ${ }^{10}$ Although $\mathrm{CO}_{2}$ exposure can be decreased during colonoscopy by following this study's procedure, the study also had several limitations, such as the small number of enrolled cases and the fact that a colonoscopy expert performed the procedures. In conclusion, $\mathrm{CO}_{2}$ insufflation during colonoscopy can decrease the symptoms of abdominal pain and discomfort during and after colonoscopy, but is more effective in reducing postprocedural pain than real-time insertion pain. Thus, $\mathrm{CO}_{2}$ insufflation can even be helpful for decreasing postprocedural pain in sedated procedures, after the sedative effect wears off. Moreover, there was no impact on procedure quality, including cecal intubation and procedure time. Although $\mathrm{CO}_{2}$ insufflation did not increase procedure-related complications or $\mathrm{ETCO}_{2}$ levels, there is very limited evidence for safety of $\mathrm{CO}_{2}$ use in high-risk patient groups. Thus, $\mathrm{CO}_{2}$ insufflation, instead of room air, can be used routinely for colonoscopy in patients without specific risk factors.

\section{WATER-ASSISTED COLONOSCOPY}

Water-assisted colonoscopy was first reported in 1984 as a water immersion (WI) method, which facilitated passage through a sigmoid colon with diverticulosis. ${ }^{11}$ In this method, water was infused while minimizing AI during intubation to facilitate scope passage. The basic concept of WI is that water is used instead of gas to distend the colon to visualize the way forward during intubation. A lumen distended with water appears to be minimally distended and angulation is reduced compared to that with AI. Air pockets encountered during scope insertion can also be suctioned with sufficient

Table 1. Comparison of Water Assisted Method and Air Insufflation Method Regarding Pain Reduction

\begin{tabular}{lcccc}
\hline Study & Number & Sedation & Pain score reduction (WI-AI) & p-value \\
\hline WI method & & & & -1.7 \\
\hline Brocchi et al. $(2008)^{18}$ & 170 & None & -0.2 & 0.001 \\
\hline Park et al. $(2010)^{19}$ & 39 & None & -1.2 & 0.894 \\
\hline Leung et al. $(2010)^{20}$ & 114 & Minimal & -0.9 & 0.001 \\
\hline Hsieh et al. $(2011)^{21}$ & 90 & Minimal & -1.4 & 0.021 \\
\hline Hsieh et al. $(2011)^{22}$ & 51 & Minimal & -1.1 & 0.004 \\
\hline Radaelli et al. $(2010)^{23}$ & 114 & On-demand & -1.9 & 0.001 \\
\hline Pohl et al. $(2011)^{16}$ & 58 & On-demand & $<0.05$ \\
\hline WE method & & & -2.8 & 0.0002 \\
\hline Leung et al. $(2009)^{24}$ & 28 & Minimal & -3 & 0.002 \\
\hline Leung et al. $(2010)^{25}$ & 40 & None & -2.6 & 0.012 \\
\hline Leung et al. $(2011)^{26}$ & 50 & On-demand & -2.9 & $<0.0005$ \\
\hline Cadoni et al. $(2015)^{17}$ & 209 & On-demand & & \\
\hline
\end{tabular}

WI, water immersion; AI, air insufflation; WE, water exchange. 
water infusion. After the scope reaches the cecum, suction removal of water is performed during the withdrawal phase of colonoscopy, allowing inspection of the mucosa. However, the method has varied in the literature. Since WI was introduced in the 1980s, several later studies reported advantages and methodologies, such as speeding up intubation and providing warm water instillation to counter colonic spasm. ${ }^{12,13}$ In retrospective studies, WI showed a higher cecal intubation rate than the air method and similar pain scores between sedated and unsedated groups, suggesting the possibility of WI as a pain-reducing technique without sedation. ${ }^{14,15} \mathrm{Sev}$ eral later RCTs comparing pain scores for WI and AI with minimal sedation have been reported (Table 1). ${ }^{16-26}$ Beyond comparing pain scores, most studies evaluated the impact on colonoscopy procedures, including cecal intubation and the adenoma detection rate. Although most published RCTs showed reduced pain during colonoscopy, WI could be affected if the bowel preparation was inadequate. ${ }^{16}$ The water exchange (WE) method, modified from WI, was developed by Leung et al. ${ }^{27}$ as the least painful, scheduled unsedated colonoscopy procedure. The WE method involves continuous water infusion and suction of residual feces and air to clear the view, with no AI. Maintaining suction and water infusion cleared the view of residual feces and enhanced the adenoma detection rate, but suctioning dirty water and replacing clean water during insertion is time-consuming. WE has major limitations in terms of time, with WE during insertion and a longer learning period, but is superior to WI for painless colonoscopy and an improved adenoma detection rate, based on a limited number of RCTs. ${ }^{28,29}$ A meta-analysis and systematic review compared AI and water-aided methods, including WI and WE, for pain score, adenoma detection rate, and requirements for sedation; both WI and WE were superior to AI regarding procedure pain. ${ }^{30,31}$ Recently, several trials have compared water-aided colonoscopy with $\mathrm{CO}_{2}$ insufflation, and performed head-to-head comparisons using WI, WE, and $\mathrm{CO}_{2} \cdot{ }^{17,32-34}$ Compared with $\mathrm{AI}$ and $\mathrm{CO}_{2}$, WI and WE significantly reduced colonoscopy insertion pain, and WE was the least painful technique.

\section{ROBOTIC COLONOSCOPY}

Recent advances in robotic colonoscopy can also overcome insertion pain. Several robotic colonoscopy systems have been introduced, with limited human studies. These systems generate internal force and need no or minimal external pushing actions, which helps to limit discomfort and pain during insertion of the scope. Although the evidence is very limited, some reports of robotic techniques have shown pain reduc- tion during procedures.

\section{Endotics}

The Endotics System (Era Endoscopy, Peccioli, Italy) consists of a sterile, disposable probe (E-Worm) and a workstation. The probe has a head, a steerable tip, a flexible body, and a thin tail. The workstation allows the endoscopist to control the disposable probe using a hand-held console. The operator can steer the probe head in any direction, elongate the probe body to move it forward, and control rinsing, insufflation, and suction. Small-scale studies have been reported with Endotics, showing superiority in pain reduction versus conventional colonoscopy, but prolonged insertion times and a relatively low cecal intubation rate need to be overcome. ${ }^{35,36}$

\section{NeoGuide Endoscopy System}

The NeoGuide Endoscopy System (NES; NeoGuide Systems Inc., Los Gatos, CA, USA) system is similar to a conventional endoscope connected to a PC workstation. The system was designed to traverse the natural shape of the colon, based on a computerized map, so that less pressure is needed, and it can reduce the incidence of looping significantly. Only one clinical trial has been reported on the feasibility of the NES system, showing a high success rate for cecal intubation, but still a high looping incidence (40\%). There has been no further trial. ${ }^{37}$

\section{Invendoscope}

The Invendoscope (Invendo Medical, Garden City, NY, USA) is a single-use, hand-held controlled colonoscope, with a $10-\mathrm{mm}$ inner sheath. This disposable device is similar to conventional endoscopes, allowing for insufflation, rinsing, and suction with a 3.1-mm working channel. Insertion and withdrawal of the colonoscope is controlled by a hand-held control unit. According to the reported evidence, the Invendoscope showed a low pain/discomfort score. ${ }^{38}$

\section{CONCLUSIONS}

The $\mathrm{CO}_{2}$ insufflation method is used widely during colonoscopy, including therapeutic procedures. Previous RCTs have shown that $\mathrm{CO}_{2}$ gas is a good option for reducing pain and discomfort during and after a procedure. However, a recent meta-analysis showed that $\mathrm{CO}_{2}$ insufflation was more effective in reducing postprocedure pain than pain during the procedure. There is still limited evidence for the safe use of $\mathrm{CO}_{2}$ insufflation in high-risk patients.

WI, and the recently modified WE method, are good options for reducing intra- and postprocedural pain and dis- 
comfort compared with $\mathrm{AI}$ and $\mathrm{CO}_{2}$ insufflation. Moreover, there is no safety limitation in using either technique. WE is the best modality to reduce patient discomfort and enhance the adenoma detection rate, although the WE procedure itself is time-consuming and requires a learning period.

Several robotic colonoscopy methods have shown favorable results in reducing procedure-related pain and discomfort. They have not yet been widely adopted and have very limited supporting evidence.

\section{Conflicts of Interest}

The author has no financial conflicts of interest.

\section{REFERENCES}

1. Rex DK, Schoenfeld PS, Cohen J, et al. Quality indicators for colonoscopy. Gastrointest Endosc 2015;81:31-53.

2. GE Technology Assessment Committee, Maple JT, Banerjee S, et al. Methods of luminal distention for colonoscopy. Gastrointest Endosc 2013;77:519-525.

3. Saltzman HA, Sieker HO. Intestinal response to changing gaseous environments: normobaric and hyperbaric observations. Ann N Y Acad Sci 1968;150:31-39.

4. Hussein AM, Bartram CI, Williams CB. Carbon dioxide insufflation for more comfortable colonoscopy. Gastrointest Endosc 1984;30:68-70.

5. Dellon ES, Hawk JS, Grimm IS, Shaheen NJ. The use of carbon dioxide for insufflation during GI endoscopy: a systematic review. Gastrointest Endosc 2009;69:843-849.

6. Wu J, Hu B. The role of carbon dioxide insufflation in colonoscopy: a systematic review and meta-analysis. Endoscopy 2012;44:128-136.

7. Wang $\mathrm{WL}, \mathrm{Wu} \mathrm{ZH}$, Sun Q, et al. Meta-analysis: the use of carbon dioxide insufflation vs. room air insufflation for gastrointestinal endoscopy. Aliment Pharmacol Ther 2012;35:1145-1154.

8. Memon MA, Memon B, Yunus RM, Khan S. Carbon dioxide versus air insufflation for elective colonoscopy: a meta-analysis and systematic review of randomized controlled trials. Surg Laparosc Endosc Percutan Tech 2016;26:102-116.

9. Bretthauer M, Lynge AB, Thiis-Evensen E, Hoff G, Fausa O, Aabakken L. Carbon dioxide insufflation in colonoscopy: safe and effective in sedated patients. Endoscopy 2005;37:706-709.

10. Chen PJ, Li CH, Huang TY, et al. Carbon dioxide insufflation does not reduce pain scores during colonoscope insertion in unsedated patients: a randomized, controlled trial. Gastrointest Endosc 2013;77:79-89.

11. Falchuk ZM, Griffin PH. A technique to facilitate colonoscopy in areas of severe diverticular disease. N Engl J Med 1984;310:598.

12. Baumann UA. Water intubation of the sigmoid colon: water instillation speeds up left-sided colonoscopy. Endoscopy 1999;31:314-317.

13. Church JM. Warm water irrigation for dealing with spasm during colonoscopy: simple, inexpensive, and effective. Gastrointest Endosc 2002;56:672-674.

14. Leung JW, Mann S, Leung FW. Options for screening colonoscopy without sedation: a pilot study in United States veterans. Aliment Pharmacol Ther 2007;26:627-631.

15. Leung FW, Aharonian HS, Leung JW, Guth PH, Jackson G. Impact of a novel water method on scheduled unsedated colonoscopy in U.S. veterans. Gastrointest Endosc 2009;69(3 Pt 1):546-550.

16. Pohl J, Messer I, Behrens A, Kaiser G, Mayer G, Ell C. Water infusion for cecal intubation increases patient tolerance, but does not improve intubation of unsedated colonoscopies. Clin Gastroenterol Hepatol 2011;9:1039-1043.e1.
17. Cadoni S, Falt P, Gallittu P, et al. Water exchange is the least painful colonoscope insertion technique and increases completion of unsedated colonoscopy. Clin Gastroenterol Hepatol 2015;13:1972-1980.e1-e3.

18. Brocchi E, Pezzilli R, Tomassetti P, Campana D, Morselli-Labate AM, Corinaldesi R. Warm water or oil-assisted colonoscopy: toward simpler examinations? Am J Gastroenterol 2008;103:581-587.

19. Park SC, Keum B, Kim ES, et al. Usefulness of warm water and oil assistance in colonoscopy by trainees. Dig Dis Sci 2010;55:2940-2944.

20. Leung CW, Kaltenbach T, Soetikno R, Wu KK, Leung FW, Friedland $\mathrm{S}$. Water immersion versus standard colonoscopy insertion technique: randomized trial shows promise for minimal sedation. Endoscopy 2010;42:557-563.

21. Hsieh YH, Lin HJ, Tseng KC. Limited water infusion decreases pain during minimally sedated colonoscopy. World J Gastroenterol 2011;17:2236-2240

22. Hsieh YH, Tseng KC, Hsieh JJ, Tseng CW, Hung TH, Leung FW. Feasibility of colonoscopy with water infusion in minimally sedated patients in an Asian Community Setting. J Interv Gastroenterol 2011;1:185-190.

23. Radaelli F, Paggi S, Amato A, Terruzzi V. Warm water infusion versus air insufflation for unsedated colonoscopy: a randomized, controlled trial. Gastrointest Endosc 2010;72:701-709.

24. Leung JW, Mann SK, Siao-Salera R, et al. A randomized, controlled comparison of warm water infusion in lieu of air insufflation versus air insufflation for aiding colonoscopy insertion in sedated patients undergoing colorectal cancer screening and surveillance. Gastrointest Endosc 2009;70:505-510.

25. Leung FW, Harker JO, Jackson G, et al. A proof-of-principle, prospective, randomized, controlled trial demonstrating improved outcomes in scheduled unsedated colonoscopy by the water method. Gastrointest Endosc 2010;72:693-700.

26. Leung J, Mann S, Siao-Salera R, et al. A randomized, controlled trial to confirm the beneficial effects of the water method on U.S. veterans undergoing colonoscopy with the option of on-demand sedation. Gastrointest Endosc 2011;73:103-110.

27. Leung FW, Leung JW, Mann SK, Friedland S, Ramirez FC. The water method significantly enhances patient-centered outcomes in sedated and unsedated colonoscopy. Endoscopy 2011;43:816-821.

28. Hsieh YH, Koo M, Leung FW. A patient-blinded randomized, controlled trial comparing air insufflation, water immersion, and water exchange during minimally sedated colonoscopy. Am J Gastroenterol 2014;109:1390-1400.

29. Leung FW. Water-aided colonoscopy. Gastroenterol Clin North Am 2013;42:507-519.

30. Rabenstein T, Radaelli F, Zolk O. Warm water infusion colonoscopy: a review and meta-analysis. Endoscopy 2012;44:940-951.

31. Leung FW, Amato A, Ell C, et al. Water-aided colonoscopy: a systematic review. Gastrointest Endosc 2012;76:657-666.

32. Garborg K, Kaminski MF, Lindenburger W, et al. Water exchange versus carbon dioxide insufflation in unsedated colonoscopy: a multicenter randomized controlled trial. Endoscopy 2015;47:192-199.

33. Falt P, Liberda M, Smajstrla V, et al. Combination of water immersion and carbon dioxide insufflation for minimal sedation colonoscopy: a prospective, randomized, single-center trial. Eur J Gastroenterol Hepatol 2012;24:971-977.

34. Amato A, Radaelli F, Paggi S, Baccarin A, Spinzi G, Terruzzi V. Carbon dioxide insufflation or warm-water infusion versus standard air insufflation for unsedated colonoscopy: a randomized controlled trial. Dis Colon Rectum 2013;56:511-518.

35. Tumino E, Sacco R, Bertini M, Bertoni M, Parisi G, Capria A. Endotics system vs colonoscopy for the detection of polyps. World J Gastroenterol 2010;16:5452-5456.

36. Cosentino F, Tumino E, Passoni GR, Morandi E, Capria A. Functional evaluation of the endotics system, a new disposable self-propelled robotic colonoscope: in vitro tests and clinical trial. Int J Artif Organs 2009;32:517-527. 


\section{$C_{\text {cunwca enooscopy }}$}

37. Eickhoff A, van Dam J, Jakobs R, et al. Computer-assisted colonoscopy (the NeoGuide Endoscopy System): results of the first human clinical trial ("PACE study"). Am J Gastroenterol 2007;102:261-266.
38. Groth S, Rex DK, Rösch T, Hoepffner N. High cecal intubation rates with a new computer-assisted colonoscope: a feasibility study. Am J Gastroenterol 2011;106:1075-1080. 